\title{
Bioequivalence Study of Imatinib Formulations that Contain 400 mg in Healthy Colombians
}

\section{Vargas $\mathbf{M}^{1 *}$ and Villarraga $\mathrm{E}^{2}$}

${ }^{1}$ Pharmacologist, Scientific Director Unidad de Farmacología Universidad de la Sabana, Bogotá, Colombia

${ }^{2}$ Pharmacologist, Study Medical Coordinator, Bogotá, Colombia

\begin{abstract}
A study with the aim to compare the bioavailability of two 400 mg imatinib formulations, test product Zeite ${ }^{\circledR}$ from Laboratorio Synthesis S.A.S., Colombia, and reference product Glivec ${ }^{\circledR}$ from Novartis Pharma, and determine if bioequivalence can be declared, was runned. It was an open, four periods and two pre-randomized sequences, crossed study, with a $400 \mathrm{mg}$ single dose in fastened and fed conditions, in 30 healthy Colombian volunteers; wash time was 7 days in between periods, with sampling between 0 and 72 hours after drug administration, which was randomly administered in each period. The analytical method used was high performance liquid chromatography with ultraviolet detector, HPLC UV for plasma identification and quantification of imatinib. The confidence interval of $90 \%$ of parameters $C_{\max }$, AUCall and AUCO-Inf, were taken to statistical analysis and were found, according to the european guidelines for research, which allowed to declare bioequivalence and interchangeability between the products from Laboratorios Synthesis S.A.S. and the reference product from Laboratory Novartis Pharma
\end{abstract}

Keywords: Bioequivalence; Imatinib; Oncologic; Pharmacokinetics

\section{Introduction}

Imatinib is a tyrosine kinase protein inhibitor, from the tyrosine group, which powerfully inhibits Bcr-Abl tyrosine kinase in vitro, at the cellular level, and in vivo. The compound selectively inhibits proliferation, and induces apoptosis in cell lines. imatinib is indicated in the treatment of patients with chronic myeloid leukemia (CML), positive Philadelphia chromosome $(\mathrm{Ph}+)(\mathrm{bcr}-\mathrm{abl})$ of recent diagnosis, for whom bone marrow transplantation is not considered as a first-line treatment [1].

Imatinib inhibits the tyrosine kinase produced by the chromosomal abnormality created by the Philadelphia chromosome, abnormality that causes chronic myeloid leukemia. It also works in patients with acute lymphoblastic leukemia. In vivo the compound shows antitumor activity in animal models using Bcr-Abl positive tumor cells.

Imatinib is also a tyrosine kinase receptor inhibitor for plateletderived growth factor (PDGF), for stem cell factor (SGF), c-Kit, and inhibits cellular processes mediated by both growth factors.

In vitro, imatinib inhibits proliferation and induces apoptosis in gastrointestinal stromal tumor cells (GIST), which express an active kit mutation [2]. The pharmacokinetics of imatinib have been evaluated in a dosage range of 25 to $1000 \mathrm{mg}$.

Plasma pharmacokinetic profiles were analyzed on day 1 and day 7 or day 28, when plasma concentrations had reached steady state. After oral administration, the mean absolute bioavailability for imatinib is $98 \%$.

Administration with a high fat meal minimally reduces the rate of absorption ( $11 \%$ reduction in $\mathrm{C}_{\max }$ and prolongation of $\mathrm{t}_{\max } 1.5 \mathrm{~h}$ ), with a small reduction in AUCall (7.4\%) [3].

Imatinib bounds extensively to plasma proteins (95\%), mainly to albumin and alpha-acid-glycoprotein. Imatinib is metabolized to the $\mathrm{N}$-demethylated piperazine derivative, which shows in vitro similar power to that of the initial compound, although its AUC all is only $16 \%$ of the imatinib's AUCall.

Following the administration of a dose of imatinib marked with carbon 14, the radioactivity corresponding to imatinib and its metabolite was $65 \%$ of the total radioactivity, and the rest corresponding to other metabolites [4].

Imatinib is classified as category $\mathrm{C}$ at risk in pregnancy. There are no adequate data on the use of this drug in pregnant women. However, as animal studies have shown reproductive toxicity and the potential risk to the fetus is unknown, imatinib should not be used during pregnancy unless clearly necessary.

Treatment should be started by an experienced physician in the diagnosis and treatment of patients with chronic myeloid leukemia (CML), positive Philadelphia chromosome recently diagnosed $(\mathrm{Ph}+)$ (bcr-abl), for whom bone marrow transplantation is not considered first-line treatment.

The current report corresponds to the results of the pharmacokinetic study in healthy volunteers with a single dose regimen of $400 \mathrm{mg}$, intended to evaluate the comparative bioavailability of the imatinib formulations, between test product Zeite from Synthesis S.A.S. (Colombia) and reference product Glivec from Novartis Pharma, in fasting and fed conditions.

\section{Materials and Methods}

\section{Study formulations}

Test product: Zeite, $400 \mathrm{mg}$ imatinib tablets, manufactured and distributed in Colombia by Synthesis Laboratory, Lot E-1016 F: F $02-$ 2016.

${ }^{*}$ Corresponding author: Vargas M, D.D.S., Pharmacologist, Scientific Director Unidad de Farmacología Universidad de la Sabana, Bogotá, Colombia, Tel: 55523-34 Ext. 8106; E-mail: mauricio.vargas@unisabana.edu.co

Received June 14, 2017; Accepted July 20, 2017; Published July 31, 2017

Citation: Vargas M, Villarraga E (2017) Bioequivalence Study of Imatinib Formulations that Contain $400 \mathrm{mg}$ in Healthy Colombians. J Bioequiv Availab 9: 483-488. doi: 10.4172/jbb. 1000349

Copyright: @ 2017 Vargas M, et al. This is an open-access article distributed under the terms of the Creative Commons Attribution License, which permits unrestricted use, distribution, and reproduction in any medium, provided the original author and source are credited. 
Reference product: Glivec', 400 mg imatinib tablets, manufactured and distributed by Novartis Pharma. Lot S0223 F: F 06/2015.

\section{Subjects}

30 Colombian volunteers, between men and not pregnant women, with ages between 18 and 55 years old, with Body Mass Index (BMI) between $18-30 \mathrm{~kg} / \mathrm{m}^{2}$ [5]. Clinically diagnosed as healthy by the Study Coordinator Physician after evaluating both clinical laboratories and the physical examination, and who signed the Informed Consent as described in the corresponding procedure, were the inclusion criteria. Positive pregnancy test, history of alcoholism, blood dyscrasias or proteinuria, impaired hepatic or renal function, was considered as exclusion factors.

\section{Obtaining the informed consent}

The Protocol and Informed Consent were authorized under code BIO 077 by the Ethics Committee in Clinical Investigation (CEIC) of Clínica de La Universidad de la Sabana, which is governed by the legal and ethical guidelines in Resolutions 008430 of 1993 and 002378 of 2008 of the Ministerio de la Protección Social de Colombia, the World Conference on Harmonization for Good Clinical Practices in institutions that conduct research in humans, and by the principles of World Medical Assembly published in the Declaration of Helsinki, last reviewed in 2013 [5].

Volunteers were given a talk, intended to explain in detail the study, emphasizing the drug type, dose, possible adverse reactions, amount of blood that was going to be taken for samples on each study phase, materials to obtain the samples, health team in charge of taking and supervising the samples, and dietary restrictions they would face; all questions that were asked by the volunteers were solved, so they could freely decide to participate in the study. After that, each one of the volunteers signed the Informed Consent.

\section{Study design}

It was an open, randomized, four periods and two sequences, crossed study. Wash time was 7 days in between periods, in fastened and fed conditions. Three days before starting each period of the study, the volunteers had to abstain from taking drugs, alcohol and any food or drink containing methylxanthines. These restrictions were maintained throughout the time the samples were taken. All volunteers were randomized to be assigned to the treatment sequence.

\section{Administration scheme}

For periods 1 and 2 the volunteers maintained a 10-hour fast before the administration of the drug. The randomized drug dose was administered with $200 \mathrm{ml}$ of water. The dose given in each period was $400 \mathrm{mg}$ (1 Tablet). This dose is related to the potency requested in the EMA guide [6]. The volunteers only received food four hours after having received the formulation, meaning after sampling 5 , corresponding to hour 10:00 a. $\mathrm{m}$.

During periods 3 and 4, the volunteers received standardized meals, and 30 minutes later they received the drug corresponding to the randomization that was performed. The team that took the samples consisted of a physician and a licensed nurse. Blood samples were taken with the use of a Vacutainer by venopuncture in the upper limb. The sample taken immediately before the drug administration was named sample time 0 . All volunteers received either the test or the reference product by randomization, and 12 venous blood samples were taken during these times: 0 hours (immediately before drug administration) 1 ,
$2,3,4,5,6,8,12,24,48$ and $72 \mathrm{hrs}$ after. Samples were labeled for their identification, and centrifuged at 3,000 rpm for 30 minutes. Plasma was transferred to a previously labeled tube and frozen at $-80^{\circ} \mathrm{C}$ for further analysis. After 7 days of wash time the administration was repeated, completing periods 2,3 and 4 .

For the study in fed conditions, volunteers received standardized feeding, which was designed by the Nutrition Department of Clínica de La Sabana, based on a high fat content diet and adequately balanced in nutritional content. The information of nutritional content provided to volunteers is presented below (Table 1).

\section{Validation of the analytical method}

The validation of the bioanalytical method was performed by high performance liquid chromatography (HPLC) for the quantification of imatinib in human plasma, meeting all the criteria for acceptability of selectivity, sensitivity, linearity, robustness, accuracy, precision, stability of the samples and limit of quantification, presented in the report EBA160516-0189 by the Laboratory Delivery Technologies in Sabaneta - Colombia.

\section{Description of imatinib extraction from human plasma}

$950 \mu \mathrm{L}$ of the test sample was added to a screw cap centrifuge tube for sedimentation containing $50 \mu \mathrm{L}$ of internal standard and $2.0 \mathrm{~mL}$ of methanol. This mixture was vortexed for 1 minute to precipitate the proteins; subsequently, centrifuged at $5000 \mathrm{rpm}$ for 15 minutes. The supernatant was filtered and injected into the chromatographic system [7].

\section{Buffer preparation (K2HPO4 $10 \mathrm{mM}$ + trimethylamine (TEA) $0.5 \% \mathrm{pH} 6.0$ )}

A solution of $1.36 \mathrm{~g}$ of dibasic potassium phosphate was prepared in $1 \mathrm{~L}$ of water. $4 \mathrm{~mL}$ of Tea and $1 \mathrm{~mL}$ of concentrated $\mathrm{H}_{3} \mathrm{PO}_{4}$ were added. It was adjusted to $\mathrm{pH} 6.0+/-0.05$ with concentrated phosphoric acid and was filtered by $0.45 \mu \mathrm{m}$ membrane.

\section{Chromatographic conditions}

We use Column: $\mathrm{C} 18,4,6 \mathrm{~mm} \times 150 \mathrm{~mm}, 5 \mu \mathrm{m}$ a $40^{\circ} \mathrm{C}$ with use the detector UV wavelength $265 \mathrm{~nm}$, the injection volume of $50 \mu \mathrm{l}$ and flow $1.0 \mathrm{~mL} / \mathrm{min}$ with mobile phase: Buffer acetonitrile: methanol $(42: 34: 24 \mathrm{v} / \mathrm{v})$.

The limit of detection is $17.3 \mathrm{mg} / \mathrm{mL}$ and the limit of quantification is $50.0 \mathrm{mg} / \mathrm{ml}$. Both limits are low, which allows to make a calibration curve in a broader range towards lower concentrations. The quantification range is $50 \mathrm{mg} / \mathrm{ml}$ to $2000 \mathrm{mg} / \mathrm{ml}[8,9]$.

\section{Pharmacokinetic analysis}

The Pharmacokinetic Analysis was performed by WinNonlin 5.3 program (Pharsight Corporation, Cary USA), adjusted to a noncompartmental analysis. The maximum concentration $\left(\mathrm{C}_{\max }\right)$ and the time to reach it $\left(t_{\max }\right)$ were directly obtained from the serum concentration results, as currently recommended by the FDA [10] and the EMA (European Medicines Agency) [11]. AUCall was calculated by the sum of the partial AUC: a) AUCall between time zero and the last time with detectable concentrations, calculated by the trapezoidal rule, and ensuring the calculation of at least the $80 \%$ of the AUC with

\begin{tabular}{|c|c|c|}
\hline Content & Planned (\%) & Recommended (\%) \\
\hline \%Protein & 15 & $12-15$ \\
\hline \%Fat & 35 & 2535 \\
\hline \%Carbohydrates & 57 & $55-65$ \\
\multicolumn{3}{|c|}{ Table 1: Information of nutritional. } \\
\hline
\end{tabular}


the last sample, b) AUCt-inf, calculated as the ratio Clast/ke, being C the last detectable concentration and $\mathrm{k}_{\mathrm{e}}$ the slope of the line, obtained by linear regression, from the points corresponding to the elimination phase of the drug, by linear regression of the natural logarithm of the concentrations [12]. The elimination rate constant $\left(\mathrm{k}_{\mathrm{e}}\right)$, half-life $\left(\mathrm{t}_{1 / 2}\right)$, the clearance $(\mathrm{Cl})$ and the mean residence time (MRT), adjusted to Bioavailability, were calculated after the non-compartmental analysis.

\section{Statistical analysis}

Variance Analysis (ANOVA) was used to determine possible effects for each variation factor, per sequence, period or subjects. The F-test was used with a statistical significance level of $5 \%(\alpha=0.05 \%)$. The statistical comparison of the transformed pharmacokinetic parameters on both formulations was performed using the statistical program WinNonlin version 5.3

The following bioequivalence criteria were established on the protocol: the Confidence Interval of $90 \%$ of $\mathrm{C}_{\max }$ test $/ \mathrm{C}_{\max }$ reference and last test AUCall/last reference AUCall, relations must be in the range of $80-125 \%$ of acceptability. Plus, AUCall must not be less than $80 \%$ of $\mathrm{AUC}_{0-\text { Inf }}$

\section{Results}

The selection of the volunteers did not show deviations from the protocol: of the 30 volunteers selected and included, 30 successfully completed the study in fasting conditions; in the fed study, one volunteer decided to retire, that is to say that 29 volunteers finished. The retired volunteer expressed his/her impossibility to participate in the third period of the study, with which he voluntarily retired. Otherwise, there were no cases of dropouts, withdrawals or discontinuities. Inclusion criteria were fulfilled and none of the volunteers were using any medication for their good health.

The selected subjects were healthy volunteers between male and female, and were Colombian; with average age of 31 years, ranging from 20 to 46 years old, average size $165 \mathrm{~cm}$ ranging between 145 and $180 \mathrm{~cm}$, average weight $68 \mathrm{~kg}$, ranging between 45 and $90 \mathrm{~kg}$, and an average Body Mass Index (BMI) of $24.7 \mathrm{Kg} / \mathrm{cm}^{2}$, ranging between 19.2 and $29.6 \mathrm{Kg} / \mathrm{cm}^{2}$.

Graphs 1 and 2 show bioavailability curves obtained in fasting and fed conditions respectively. Tables 2 and 3 show the averages of the pharmacokinetic parameters obtained from all volunteers (average \pm SD) in fasting and fed conditions respectively. Tables 4 and 5 show the $90 \%$ confidence interval parameters logarithmically transformed, analysis performed to determine bioequivalence between test product from Synthesis S.A.S. and reference product Glivec from Novartis Pharma, in fasting and fed conditions respectively.

\section{Adverse events report}

The following are the consolidated results of adverse reactions presented by the feeding condition, by the studied drug, or by the compromised system, as recommended by the WHO.

Tables 6 and 7: They are also presented discriminating the presented symptomatology.

Tables 8 and 9: The reactions presented do not influence the bioequivalence analysis, because they occurred after the absorption of the drug in the case of digestive disorders, and additionally none of the volunteers needed to take medication to solve the reactions presented. Follow-up was performed, and the reactions disappeared within the first 12 hours after administration of the study drug.

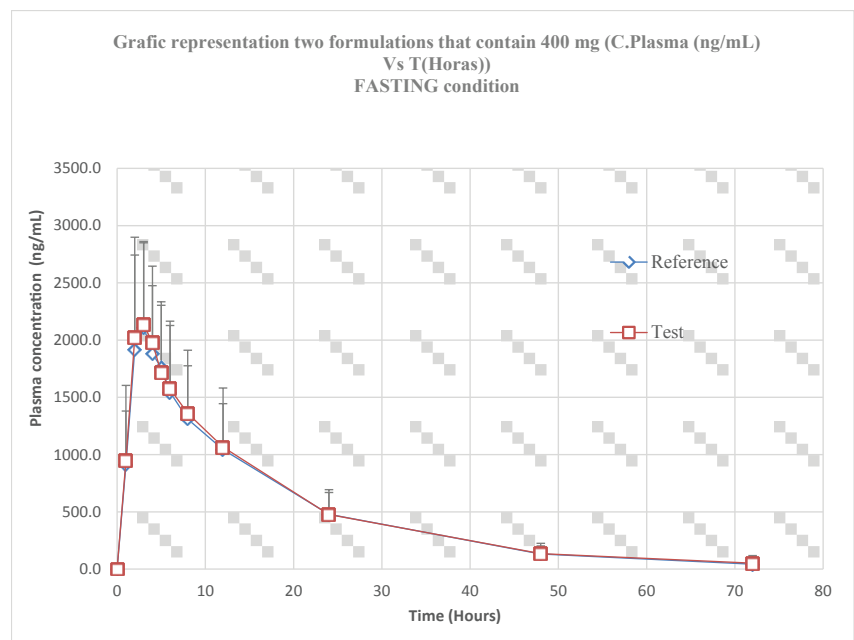

Graph 1: Curve Concentration vs. Time obtained after a $400 \mathrm{mg}$ imatinib dose of test product (Zeite ${ }^{\circledR}$ from Laboratory Synthesis S.A.S.) and reference product (Glivec ${ }^{\circledR}$ from Novartis Pharma) in fasting conditions.

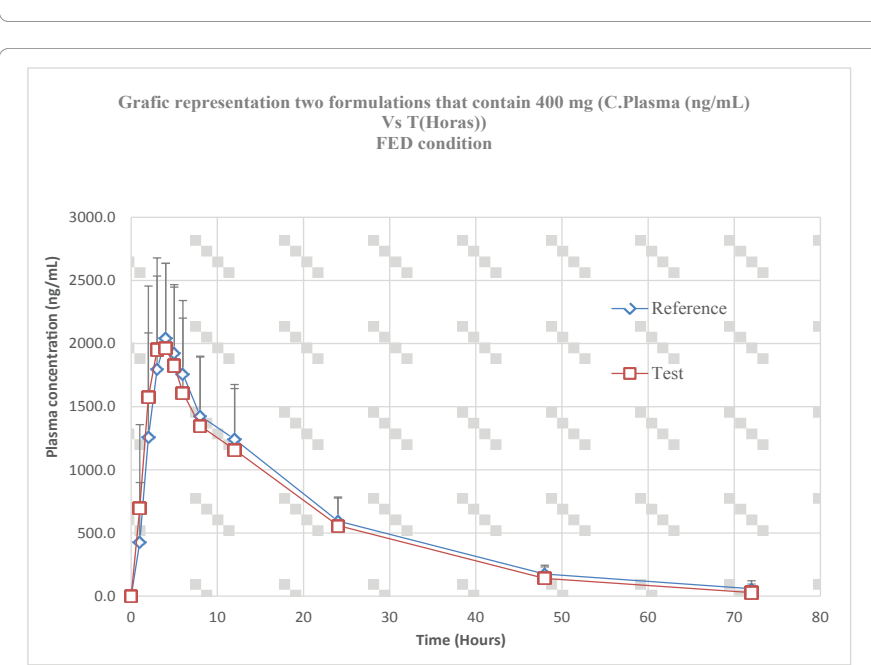

Graph 2: Curve Concentration vs. Time obtained after a $400 \mathrm{mg}$ imatinib dose of test product (Zeite ${ }^{\circledR}$ from Laboratory Synthesis S.A.S.) and reference product (Glivec ${ }^{\circledR}$ from Novartis Pharma) in fed conditions.

\section{Discussion}

The WHO, EMA, FDA and INVIMA, accept bioequivalence studies as the surrogate test that makes us think with a high degree of probability that the two drugs will have a similar efficacy and safety profile, meaning they are therapeutic equivalents [13].

This was a pharmacokinetic study in healthy volunteers with a single dose regimen, aimed at evaluating the bioequivalence of two imatinib $400 \mathrm{mg}$ formulations under fasting and fed conditions.

The bioequivalence assessment of the pharmacokinetic parameters was performed based on the plasma concentrations of imatinib as a function of time, after the evaluation of blood samples obtained from healthy volunteers. There was a decrease in adverse reactions in fed conditions, decreasing by $81.3 \%$ for the most frequently reported reaction (nausea).

The maximum plasma concentration decreases in a fed condition by an estimated $8 \%$; however, the total drug amount is increased by 
Citation: Vargas M, Villarraga E (2017) Bioequivalence Study of Imatinib Formulations that Contain 400 mg in Healthy Colombians. J Bioequiv Availab 9: 483-488. doi: 10.4172/jbb.1000349

\begin{tabular}{|c|c|c|c|c|c|c|}
\hline Treatment & Elimination Rate $(1 / \mathrm{hr})$ & Half Life (hr) & $\operatorname{tmax}(\mathrm{hr})$ & Cmax (ng/mL) & AUC 0-t (hr*ng/mL) & AUC 0-Inf (hr*ng/mL) \\
\hline Reference & 0.056 & 13.2 & 3.2 & 2370.5 & 35498.8 & 36890.9 \\
\hline SD & 0.014 & 3.9 & 1.1 & 813.4 & 12015.9 & 12330.9 \\
\hline Test & 0.054 & 13.8 & 2.9 & 2354.1 & 36188.0 & 37805.1 \\
\hline SD & 0.015 & 4.1 & 0.9 & 806.3 & 14839.0 & 15660.2 \\
\hline
\end{tabular}

Table 2: Average Pharmacokinetic Parameters, fasting condition. Pharmacokinetic parameters of 400 mg of imatinib test product Zeite ${ }^{\circledR}$ from Laboratorio Synthesis S.A.S. Colombia, and $400 \mathrm{mg}$ of imatinib reference product Glivec $^{\circledR}$ from Laboratorio Novartis Pharma, in fasting conditions.

\begin{tabular}{|c|c|c|c|c|c|c|}
\hline Treatment & $\begin{array}{c}\text { Elimination Rate (1/ } \\
\mathrm{hr})\end{array}$ & Half Life (hr) & $\operatorname{tmax}(\mathrm{hr})$ & Cmax (ng/mL) & AUC 0-t (hr*ng/mL) & AUC 0-Inf $\left(\mathrm{hr}^{*} \mathrm{ng} / \mathrm{mL}\right)$ \\
\hline Reference & 0.055 & 13.7 & 4.0 & 2182.8 & 39929.4 & 41587.9 \\
\hline SD & 0.016 & 4.1 & 1.2 & 639.3 & 14987.6 & 16213.6 \\
\hline Test & 0.060 & 12.3 & 3.6 & 2205.5 & 37535.5 & 38512.9 \\
\hline SD & 0.017 & 3.3 & 1.1 & 760.8 & 13334.8 & 13794.2 \\
\hline
\end{tabular}

Table 3: Average Pharmacokinetic Parameters. fed condition. Pharmacokinetic parameters of 400 mg of imatinib test product Zeite ${ }^{\circledR}$ from Laboratorio Synthesis S.A.S Colombia. and $400 \mathrm{mg}$ of imatinib reference product $\mathrm{Glivec}^{\circledR}$ from Laboratorio Novartis Pharma. in fed conditions.

\begin{tabular}{|c|c|c|c|c|}
\hline & & & Standard IC $90 \%$ & (Test / Reference) \\
\hline Parameter & Units & Ratio \% & 80 & 125 \\
\hline $\operatorname{Ln}($ Cmax $)$ & $\mathrm{ng} / \mathrm{mL}$ & 98.9 & 91.18 & 107.28 \\
\hline Ln(AUCall) & $\mathrm{hr} r^{*} \mathrm{~g} / \mathrm{mL}$ & 98.31 & 91.25 & 105.92 \\
\hline Ln(AUCINF_obs) & $\mathrm{hr}{ }^{*} \mathrm{ng} / \mathrm{mL}$ & 98.62 & 91.77 & 105.98 \\
\hline
\end{tabular}

Table 4: Bioequivalence Analysis (confidence interval) 80-125, fasting condition.

\begin{tabular}{|c|c|c|c|c|}
\hline \multirow[b]{2}{*}{ Parameter } & \multirow[b]{2}{*}{ Units } & \multirow[b]{2}{*}{ Ratio \% } & \multicolumn{2}{|c|}{ Standard IC $90 \%$ (Test / Reference) } \\
\hline & & & 80 & 125 \\
\hline $\operatorname{Ln}($ Cmax $)$ & $\mathrm{ng} / \mathrm{mL}$ & 99.81 & 94.70 & 105.20 \\
\hline Ln(AUCall) & $\mathrm{hr}{ }^{*} \mathrm{ng} / \mathrm{mL}$ & 94.67 & 89.14 & 100.50 \\
\hline Ln(AUCINF_obs) & $\mathrm{hr}+\mathrm{ng} / \mathrm{mL}$ & 93.54 & 87.59 & 99.88 \\
\hline
\end{tabular}

Table 5: Bioequivalence Analysis (confidence interval) 80-125, fed Condition.

\begin{tabular}{|c|c|c|c|c|}
\hline \multirow{2}{*}{} & \multicolumn{3}{|c|}{ Fasting Conditions } \\
\cline { 2 - 4 } & Ref $\%$ & (n) & 11.7 \\
\hline Nervous system disorder & 15 & 9 & 25.1 \\
\hline Digestive system disorder & 13.4 & 1 & 1 \\
\hline Dermatologic disorder & 1.7 & 1 & 0.0 \\
\hline
\end{tabular}

Table 6: Adverse Reactions in Fasting Conditions According to the WHO system. Consolidated results of adverse reactions presented for the studied drugs in fasting conditions. discriminated by the compromised system. according to the WHO.

\begin{tabular}{|c|c|c|c|}
\hline \multirow{2}{*}{} & \multicolumn{3}{|c|}{ Fed Condition } \\
\cline { 2 - 4 } & Ref \% & Test \% & (n) \\
\hline Nervous system disorder & 1.7 & 1 & 8.4 \\
\hline Digestive system disorder & 1.7 & 1 & 5 \\
\hline
\end{tabular}

Table 7: Adverse Reactions in Fed Conditions According to the WHO system. Consolidated results of adverse reactions presented for the studied drugs in fed conditions. discriminated by the compromised system. according to the WHO.

\begin{tabular}{|c|c|c|c|c|}
\hline & \multicolumn{4}{|c|}{ Fasting Conditions } \\
\hline & Ref \% & (n) & Test $\%$ & (n) \\
\hline Nausea & 11.7 & 7 & 16.7 & 10 \\
\hline Abdominal Pain & 1.7 & 1 & 1.7 & 1 \\
\hline Dizziness & 8.3 & 5 & 10 & 6 \\
\hline Headache & 6.7 & 4 & 1.7 & 1 \\
\hline Vomit & 0 & 0 & 6.7 & 4 \\
\hline Neck Sprout & 1.7 & 1 & 0 & 0 \\
\hline
\end{tabular}

Table 8: Adverse Reactions in Fasting Conditions According to Symptomatology. Consolidated results of adverse reactions presented for the studied drugs in fasting conditions. discriminated by presented symptoms. 
Citation: Vargas M, Villarraga E (2017) Bioequivalence Study of Imatinib Formulations that Contain 400 mg in Healthy Colombians. J Bioequiv Availab 9: 483-488. doi: 10.4172/jbb.1000349

\begin{tabular}{|c|c|c|c|c|}
\hline & \multicolumn{3}{|c|}{ Fed Condition } \\
\hline & Ref $\%$ & (n) & Test \% \\
\hline Nausea & 0 & 0 & 3.3 \\
\hline Abdominal Pain & 1.7 & 1 & 1.7 \\
\hline Dizziness & 0 & 0 & 1.7 \\
\hline Headache & 1.7 & 1 & 1 \\
\hline
\end{tabular}

Table 9: Adverse Reactions in Fed Conditions According to Symptomatology. Consolidated results of adverse reactions presented for the studied drugs in fed conditions discriminated by presented symptoms.

increasing the half-life. Increase in the area under the curve up to the sampling time, and up to the infinity, was $12 \%$. Regarding the test formulation delivery, we can see that it is equivalent as evidenced by the average pharmacokinetic parameters.

\section{Conclusions}

The imatinib formulation Zeite manufactured by Synthesis S.A.S., test product, and the formulation Glivec manufactured by Novartis Pharma, reference product, have pharmacokinetic parameters that allow to declare bioequivalence between the two formulations, and therefore interchangeability. We can conclude that both formulations are bioequivalent and therefore are interchangeable as described by the EMA.

\section{References}

1. Steinbach A, Clark SM, Clemmons AB (2013) Bosutinib: a novel src/abl kinase inhibitor for chronic myelogenous leukemia. J Adv Pract Oncol 4: 451.

2. Eskazan AE, Elverdi T, Yalniz FF, Salihoglu A, Ar MC, et al. (2014) The efficacy of generic formulations of imatinib mesylate in the treatment of chronic myeloid leukemia. Leuk. Lymphoma 55: 2935-2937.

3. Ostrowicz A, Mikolajczak P, Wierzbicka M, Boguradzki P (2014) Bioequivalence study of 400 and $100 \mathrm{mg}$ imatinib film-coated Tablets in healthy volunteers. Acta Pol Pharm 71: 843-854.

4. Jawhari D, AISwisi M, Ghannam M (2011) Bioavailability of a New Generic
Formulation of Imatinib Mesylate 400mg Tablets Versus Glivec in Healthy Male Adult Volunteers. J Bioequiv Availab 3: 161-164

5. Queckenberg C, Fuhr U (2009) Influence of posture on pharmacokinetics Eur Clin Pharmacol 65: 109-119.

6. European Medicines Agency (2015) Imatinib Product-Specific Bioequivalence Guidance.

7. Miura M, Takahashi N, Sawada KI (2011) Quantitative determination of imatinib in human plasma with high-performance liquid chromatography and ultraviole detection. J Chromatogra Sci 49: 412-415.

8. Paulina H (2009) Development of a quantitative chromatographic method for the determination of Imatinib and its main metabolite in human plasma.

9. Roth O, Spreux-Varoquaux $O$, Bouchet $S$, Rousselot $P$, Castaigne $S$, et al. (2010) Imatinib assay by HPLC with photodiode-array UV detection in plasma from patients with chronic myeloid leukemia: Comparison with LC-MS/MS. Clinica Chimica Acta 411: 140-146.

10. Food and Drugs Administration (2009) January, Guidance for industry Statistical Approaches to Establishing Bioequivalence.

11. The European Agency for the Evaluation of Medicinal Products, EMA (2000) Committee for Proprietary Medicinal Products (CPMP), London, UK.

12. Perry R (2010) Perspectives on the bioequivalence and therapeutic equivalence of generic formulations: An overview of the landscape. Clin Ther 32: 1796-1797.

13. WHO (1996) Pharmaceuticals Products: Guidelines On Registration Requirements to Establish Interchangeability, WHO Expert Committee on Specifications for Pharmaceutical Preparations - WHO Technical Report Series, No. 863 - Thirty-fourth Report. 